\title{
Annual changes in the concentrations of free triiodothyronine, progesterone and testosterone in prepubertal red deer (Cervus elaphus elaphus) males and females
}

\author{
J. Kuba', B. Błaszczyk, T. Stankiewicz and J. Udała \\ West Pomeranian University of Technology in Szczecin, \\ Department of Animal Reproduction Biotechnology and Environmental Hygiene, Dr. Judyma 6, 71-466 Szczecin, Poland
}

KEY WORDS: free triiodothyronine, season, puberty, sex, red deer

Received: 4 March 2015

Revised: 18 May 2015

Accepted: 15 June 2015

${ }^{1}$ Corresponding author:

e-mail: jaroslaw.kuba@zut.edu.pl

\begin{abstract}
The aim of the study was to analyse the annual changes in the concentration of free triiodothyronine, progesterone and testosterone in the serum of prepubertal red deer males and females. Blood was collected monthly from 8 stags and 8 hinds for a period of one year, beginning in November. Hormone concentrations were determined using an immunofluorescence method (TR-FIA). Monitoring of the duration of the prepubertal period, based on the progesterone concentrations in females and testosterone concentrations in the males, suggested that the prepubertal period ended in September in both sexes. The experiment revealed the annual rhythm in free triiodothyronine (FT3) secretion, with significantly higher concentrations in the winter-spring period in comparison with summer-autumn in both, males $(P<0.01)$ and females $(P<0.05)$. The results showed that the season considerably influenced the intensity of FT3 secretion in prepubertal red deer and that the secretion dynamics in both sexes were similar, however, the concentrations in the males reached higher levels than in the females in each season and across the whole experiment.
\end{abstract}

\section{Introduction}

Red deer are short-day breeders, in whom reproductive activity arises in response to shortening of the day length, therefore, in the temperate climate the mating season takes place in autumn (Asher et al., 2011). During this period, ovarian activity in females is pronounced by cyclic changes in the concentrations of sex steroids, including progesterone, whereas in males, testicular activity is manifested through the intensified production of testosterone. For this reason, changes in the concentration of progesterone in females and of testosterone in males may be an indicator of sexual activity, including entrance into puberty (Shi and Barrell, 1992; Asher et al., 2011).

Thyroid hormones (iodothyronines) play a role in both the prepubertal and pubertal periods. Among the iodothyronines, the highest biological activity at the cellular level has been observed for triiodothyronine (Cheng et al., 2010). More than 99\% of the total pool of this hormone deposited in the organism is bound by transporting proteins, but only free triiodothyronine is able to cause an effect at the cellular level (Todini et al., 2007). This is seen, for example, in thermoregulation in neonates and older individuals through stimulation of cellular oxidation processes (Gereben et al., 2008). There are also some 
differences in iodothyronine-mediated processes between young and adult animals, which result from the more intensive metabolism of growing, immature animals (Villanueva et al., 2013). Moreover, thyroid hormones are engaged in the regulation of reproduction seasonality. By the end of the mating season (and before the beginning of seasonal anoestrus) a rise in the concentrations of thyroid hormones has been observed in different species, including the red deer (Anderson and Barrell, 1998). For this reason it has been suggested that thyroid hormones may be involved in terminating the mating season (Nakao et al., 2008). With regard to the above, it seemed interesting to investigate the annual profile of triiodothyronine concentrations in animals that have not yet reached puberty. Therefore, the aim of this study was to analyse the annual changes in free triiodothyronine (FT3), progesterone $(\mathrm{P} 4)$ and testosterone $(\mathrm{T})$ concentrations in prepubertal red deer males and females.

\section{Material and methods}

The experiment was approved by the local Ethics Committee at the Faculty of Biotechnology and Animal Husbandry, West Pomeranian University of Technology in Szczecin, Poland (approval No. 29/2012).

\section{Animals and sampling}

The study was performed on red deer (Cervus elaphus elaphus) males $(\mathrm{n}=8)$ and females $(\mathrm{n}=8)$. The animals were kept in captivity at a farm in the Lubusz voivodeship. In spring, summer and autumn the animals were kept on pasture, while in winter the fodder was supplied with silage, vegetables (beets, carrots, cabbage) and cereals. Access to fresh water was unrestricted and no mineral supplementation was used. The experiment continued over the 12 months preceding puberty in the animals. Blood samples $(10 \mathrm{ml})$ were obtained from the jugular vein and in this procedure no analgesics were used. Samples of serum obtained after centrifugation (10 $\mathrm{min}, 4000 \mathrm{rpm}$ ) were stored at $-20^{\circ} \mathrm{C}$ until laboratory analysis. Samples were collected monthly from November (age of the animals: 6 months) to October the following year (age of the animals: 17 months).

\section{Free triiodothyronine assay}

The concentration of free triiodothyronine (FT3) was evaluated by an immunofluorescence method (TR-FIA) using a Delfia FT3 kit (Perkin Elmer Inc., Waltham, MA, USA) in a Wallac Victor 1420 unit (Wallac Oy, Turku, Finland). The volume of the serum samples used to assess the concentration of FT3 was $50 \mu 1$. The intra- and inter-assay coefficients of variation for measurement were $7.90 \%$ and $6.50 \%$, respectively. The sensitivity of the FT3 assay was $>2 \mathrm{pmol} \cdot 1^{-1}$. All assays were carried out in duplicate.

\section{Progesterone and testosterone assays}

The concentrations of progesterone (P4) and testosterone $(\mathrm{T})$ were evaluated by an immunofluorescence method (TR-FIA) using Delfia Progesterone and Delfia Testosterone kits (Perkin Elmer Inc., Waltham, MA, USA) in a Wallac Victor 1420 unit (Wallac Oy, Turku, Finland). The volume of the serum samples used for these assays was $25 \mu$ for both, P4 and T. The intra- and inter-assay coefficients of variation for measurement of progesterone were $4.93 \%$ and $6.97 \%$, and for testosterone $5.70 \%$ and $8.43 \%$, respectively. The sensitivities of the assays were $>0.25 \mathrm{ng} \cdot \mathrm{ml}^{-1}$ for $\mathrm{P} 4$ and $>0.09 \mathrm{ng} \cdot \mathrm{ml}^{-1}$ for T. All assays were carried out in duplicate.

\section{Statistical analysis}

Statistical analysis was performed with the Statistica 10 software package (Statsoft, Inc., 2011). The distribution of the results was evaluated with the Shapiro-Wilk test. The results were compared using repeated-measure analysis of variance, and the significance of differences between means was determined by Duncan's test. The analyses were conducted with significance levels of $P<0.01$ and $P<0.05$.

\section{Results}

\section{Free triiodothyronine and progesterone concentration changes in females}

The profile of changes in free triiodothyronine (FT3) and progesterone (P4) concentrations in the females is shown in Figure 1. Levels of FT3 were characterized by significantly $(P<0.01)$ higher concentrations during the winter-spring period $\left(6.64 \pm 1.10 \mathrm{pmol} \cdot \mathrm{1}^{-1}\right)$ than in summer-autumn $\left(4.28 \pm 1.35 \mathrm{pmol} \cdot 1^{-1}\right)$. The highest concentration of FT3 in the hinds was observed in April, $8.06 \pm 1.34 \mathrm{pmol} \cdot 1^{-1}$, and the lowest, in October, $3.74 \pm 1.17 \mathrm{pmol} \cdot 1^{-1}$.

The concentration of $\mathrm{P} 4$ in the females was at a similar level from November to August, reaching $0.98 \pm 0.41 \mathrm{ng} \cdot \mathrm{ml}^{-1}$, on average. In the following months the concentration of P4 significantly $(P<0.01)$ increased by September and October to $2.91 \pm 0.68 \mathrm{ng} \cdot \mathrm{ml}^{-1}$ and $3.04 \pm 0.72 \mathrm{ng} \cdot \mathrm{ml}^{-1}$, respectively. 


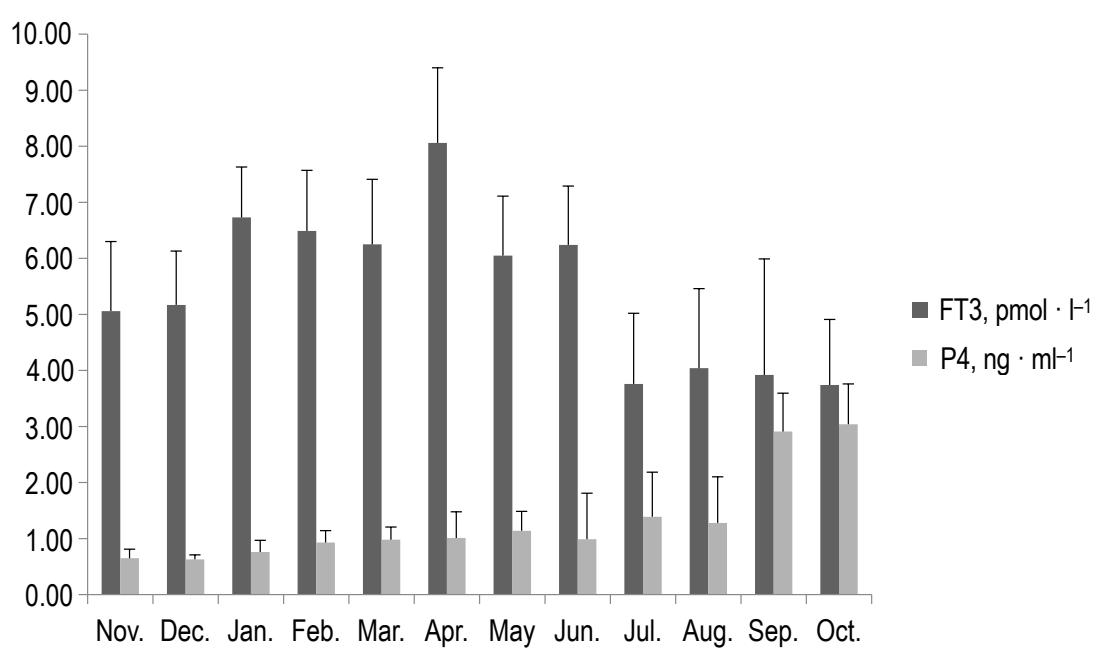

Figure 1. Mean concentration of free triiodothyronine (FT3) and progesterone (P4) in serum of red deer females in the following months of the experiment

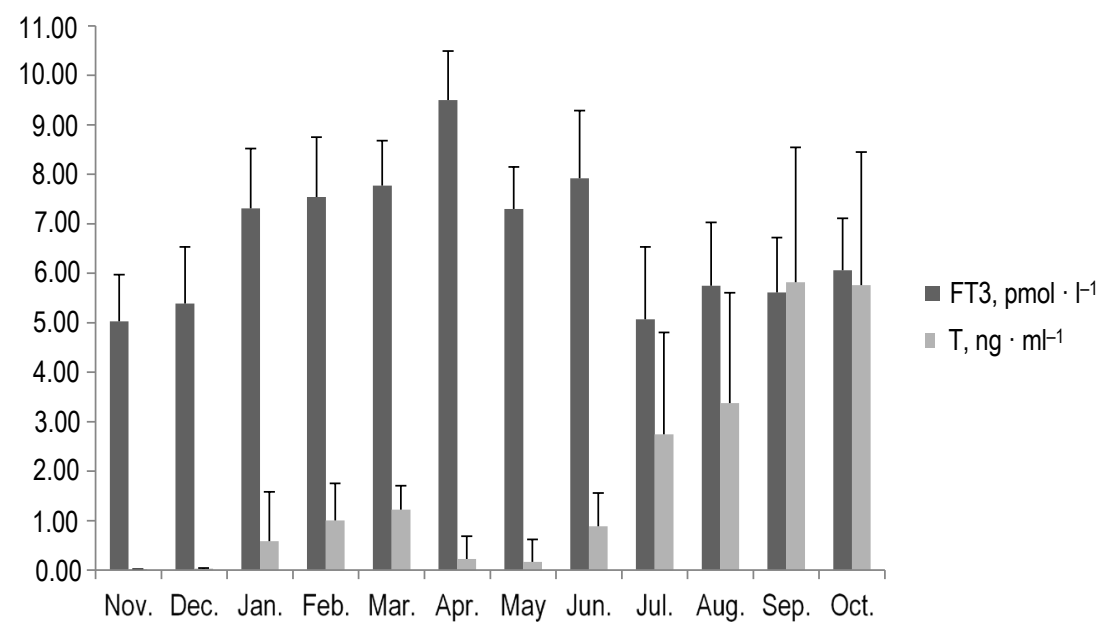

Figure 2. Mean concentration of free triiodothyronine (FT3) and testosterone (T) in serum of red deer males in the following months of the experiment

\section{Free triiodothyronine and progesterone concentration changes in males}

The dynamics of changes in free triiodothyronine (FT3) and testosterone (T) concentrations observed in the males are presented in Figure 2. The mean concentration of FT3 in the winter-spring period was $7.89 \pm 1.09 \mathrm{pmol} \cdot 1^{-1}$ and was significantly higher than in the summer-autumn period, $5.48 \pm 1.16 \mathrm{pmol} \cdot 1^{-1}$. The highest concentration was observed in April $\left(9.50 \pm 0.99 \mathrm{pmol} \cdot 1^{-1}\right)$, and the lowest in November $(5.03 \pm 0.94 \mathrm{pmol}$. $\left.1^{-1}\right)$. The mean concentration of FT3 in the stags was significantly higher than in the hinds in each season, as well as across the entire experiment (Table 1).

The profile of testosterone concentration changes in the males was characterized by low levels from
Table 1. Mean concentration of free triiodothyronine (FT3) in examined animals in the following seasons

\begin{tabular}{|c|c|c|c|c|}
\hline \multirow{2}{*}{ Indices } & \multirow{2}{*}{ Season } & Females & Males & \multirow{2}{*}{$P$} \\
\hline & & Mean \pm SD & Mean \pm SD & \\
\hline \multirow{5}{*}{$\begin{array}{l}\mathrm{FT3}, \\
\mathrm{pmol} \cdot \mathrm{I}^{-1}\end{array}$} & Spring & $6.78 \pm 1.05^{\mathrm{A}}$ & $8.11 \pm 1.07^{\mathrm{B}}$ & $<0.01$ \\
\hline & Summer & $3.91 \pm 1.58^{\mathrm{a}}$ & $5.46 \pm 1.28^{b}$ & $<0.05$ \\
\hline & Autumn & $4.67 \pm 1.12^{\mathrm{a}}$ & $5.49 \pm 1.04^{b}$ & $<0.05$ \\
\hline & Winter & $6.49 \pm 1.15^{A}$ & $7.54 \pm 1.11^{\mathrm{B}}$ & $<0.01$ \\
\hline & Total & $5.46 \pm 1.23^{\mathrm{A}}$ & $6.65 \pm 1.13^{\mathrm{B}}$ & $<0.01$ \\
\hline
\end{tabular}

$\mathrm{AB}$, ab means with different superscipts within a row are significantly different at $P<0.01$ or $P<0.05$, respectively

November to June (mean $0.517 \pm 0.479 \mathrm{ng} \cdot \mathrm{ml}^{-1}$ ), but a gradual increase in these concentrations began in summer. In September and October the levels were the highest, reaching $5.82 \pm 2.89 \mathrm{ng} \cdot \mathrm{ml}^{-1}$ and $5.72 \pm 2.96 \mathrm{ng} \cdot \mathrm{ml}^{-1}$, respectively. 


\section{Discussion}

In the study we focused on the changes in the concentration of free triiodothyronine (FT3) in prepubertal red deer hinds and stags. According to the published reports concerning red deer, the duration of the prepubertal period was evaluated on the basis of low concentrations of progesterone in the females and testosterone in the males (Asher et al., 2011; Pavitt et al., 2014). Based the observed concentrations of these hormones, we may presume that the examined animals were prepubertal from the beginning of the experiment in November to September the following year. The prepubertal period we examined in this study was characterized by similar dynamics in FT3 secretion in both sexes. The profiles of secretion were most likely caused by adaptation of metabolic processes in response to the changing seasons. In the temperate climate, the period of food abundance allows the red deer to store energy reserves for winter, when food availability is poor and the mechanisms that limit energy expenditure need to be activated (Turbill et al., 2011). This cycle of processes is regulated by many factors, including iodothyronines (Cheng et al., 2010). Thanks to these hormones it is possible to maintain a metabolic balance with respect to changes in environmental conditions. In the study by Shi and Barrell (1992), the dynamics of changes in the concentration of total triiodothyronine (T3) in adolescent red deer stags was similar to the profile shown in our work. The cited authors noted an elevated level of T3 in spring, and decreased in autumn. A higher concentration in spring was also observed in adult red deer hinds (Anderson and Barrell, 1998). However, it needs to be emphasized that there were some time discrepancies between the reports cited above and our observations of the duration of the elevated concentrations, which are probably an effect of a different latitude and climatic zone.

The thyroid is one of the organs most sensitive to variations in environmental temperature, and changes in its secretory activity in response to seasonal conditions have been shown in many species (Rasooli et al., 2004). So far, the reports do not indicate a simple scheme of regulation of triiodothyronine secretion dependent on seasonal variations, however, it can be seen that, in general, an increase in secretion covers the period of lower temperatures (in this study, winter and spring). During most of this period in a temperate climate, vegetation is visibly less abundant, and thus food availability for deer is decreased in comparison with summer-autumn (Pettorelli et al., 2005). Therefore, we can suppose that the increase in FT3 secretion occurs as a result of the necessity to mobilize energy reserves in the organism. A similar conclusion was reached by Bishop et al. (2009), who showed that in mule deer, intensification of catabolic processes took place in late winter/early spring, and that in this period the changes in the concentration of thyroid hormones were most related to changes in the animals' metabolism.

Another factor that may affect the scale of iodothyronine secretion is gender and the results obtained in our work support this assumption. The differences in FT3 secretion observed between hinds and stags may be caused by the different rate of physiological processes in females and in the males, aside from puberty. Due to the absence of puberty in the immature animals, it is impossible to unambiguously explain the observed differences in FT3 secretion by an effect of sex steroids, as was attempted in adult red deer (Chao and Brown, 1984). However, it cannot be excluded that the differences found in the prepubertal period are a consequence of the genetically programmed gender. These differences concern, for instance, the deposition and mobilization of fat tissue and its adoption as a metabolic substrate, which may act as an evolutionary response to various energy expenditures related to further stages of life (Power and Schulkin, 2008). To support our hypothesis, it is worth noticing that there are reports indicating that even in neonates, the presence of sex steroids resulting from genetic gender affects features that develop entirely during adulthood (Pavitt et al., 2014).

\section{Conclusions}

To our knowledge, this work is the first report showing the effects of differences in sex on the intensity of free triiodothyronine (FT3) secretion in prepubertal red deer females and males. Moreover, the results suggest that in young red deer, there is an annual rhythm in the secretion of FT3 that responds to seasonal variations, aside from sexual maturity and gender.

\section{References}

Anderson G.M., Barrell G.K., 1998. Effects of thyroidectomy on thyroxine replacement on seasonal reproduction in the red deer. J. Reprod. Fertil. 113, 239-250

Asher G.W., Scott I.C., Archer J.A., Ward J.F., Littlejohn R.P., 2011. Seasonal luteal cyclicity of pubertal and adult red deer (Cervus elaphus). Anim. Reprod. Sci. 125, 138-147

Bishop C.J., Watkins B.E., Wolfe L.L., Freddy D.J., White G.C., 2009. Evaluating mule deer body condition using serum thyroid hormone concentrations. J. Wildlife Manage 73, 462-467 
Chao C.C., Brown R.D., 1984. Seasonal relationships of thyroid, sexual and adrenocortical hormones to nutritional parameters and climatic factors in white-tailed deer (Odocoileus virginianus) of south Texas. Comp. Biochem. Physiol. Pt. A 77, 299-306

Cheng S.Y., Leonard J.L., Davis P.J., 2010. Molecular aspects of thyroid hormone actions. Endocr. Rev. 31, 139-170

Gereben B., Zavacki A.M., Ribich S., Kim B.W., Huang S.A., Simonides W.S., Zeöld A., Bianco A.C., 2008. Cellular and molecular basis of deiodinase-regulated thyroid hormone signaling. Endocr. Rev. 29, 898-938

Nakao N., Ono H., Yoshimura T., 2008. Thyroid hormones and seasonal reproductive neuroendocrine interactions. Reproduction 136, 1-8

Pavitt A.T., Walling C.A., Pemberton J.M., Kruuk L.E.B., 2014. Heritability and cross-sex genetic correlations of early-life circulating testosterone levels in a wild mammal. Biol. Lett. 10, 20140685, http://dx.doi.org/10.1098/rsbl.2014.0685

Pettorelli N., Mysterud A., Yoccoz N.G., Langvatn R., Stenseth N.C., 2005. Importance of climatological downscaling and plant phenology for red deer in heterogeneous landscapes. Proc. Biol. Sci. 272, 2357-2364

Power M.L., Schulkin J., 2008. Sex differences in fat storage, fat metabolism, and the health risks from obesity: possible evolutionary origins. Brit. J. Nutr. 99, 931-940
Rasooli A., Nouri M., Khadjeh G.H., Rasekh A., 2004. The influences of seasonal variations on thyroid activity and some biochemical parameters of cattle. Iran. J. Vet. Res. 5, 1383-1391

Shi Z.D., Barrell G.K., 1992. Requirement of thyroid function for the expression of seasonal reproductive and related changes in red deer (Cervus elaphus) stags. J. Reprod. Fertil. 94 $251-259$

StatSoft, Inc., 2011. STATISTICA (data analysis software system). Version 10, www.statsoft.com

Todini L., Malfatti A., Valbonesi A., Trabalza-Marinucci M., Debenedetti A., 2007. Plasma total T3 and T4 concentrations in goats at different physiological stages, as affected by the energy intake. Small Ruminant Res. 68, 285-290

Turbill C., Ruf T., Mang T., Arnold W., 2011. Regulation of heart rate and rumen temperature in red deer: effects of season and food intake. J. Exp. Biol. 214, 963-970

Villanueva I., Alva-Sánchez C., Pacheco-Rosado J., 2013. The role of thyroid hormones as inductors of oxidative stress and neurodegeneration. Oxid. Med. Cell Longev. 2013, 218145, http://dx.doi.org/10.1155/2013/218145 